\title{
Analysis of Fuel Temperature Reactivity Coefficient of the PWR using WIMS Code
}

\author{
Santo Paulus Rajagukguk ${ }^{1 *}$, Syaiful Bakhri ${ }^{2}$, Tukiran Surbakti ${ }^{2}$ \\ ${ }^{1}$ Department of Physics, FMIPA, UNIMED, Medan, 20221, Indonesia \\ ${ }^{2}$ Research Center for Nuclear Reactor Technology and Safety, Research Organization for Nuclear Energy, BRIN, Kawasan Puspiptek Gd.80, \\ Tangerang Selatan, 15314, Banten, Indonesia,
}

\section{ARTICLE INFO}

Article history:

Received: 10 May 2021

Received in revised form: 24 June 2021

Accepted: 28 June 2021

\section{Keywords:}

Reactivity coefficient

PWR reactor

Moderator

Fuel pellet

WIMSD-5B

\begin{abstract}
A B S T R A C T
The Fuel Temperature Reactivity Coefficient (FTRC) is an important parameter in design, control, and safety, particularly in PWR reactor. It is then very important to validate any new library for an accurate prediction of this parameter. The objective of this work is to determine the value of the FTRC parameter using the new WIMDS library based on ENDF/BVIII.0 nuclear data files. For this purpose, it is used a set of light water moderated lattice experiments as the PWR-1175 MWe experiment critical reactors, the reactor using $\mathrm{UO}_{2}$ fuel pellet. The analysis is used with WIMSD-5B lattice code with original cross-section libraries and WIMSD-5B with ENDF/B-VIII.0 new cross-section libraries. The results showed that the fuel temperatures reactivity coefficients for the PWR reactor using original libraries is $-3.10 \mathrm{pcm} / \mathrm{K}$ with enrichment of $3.1 \%$ but for ENDF/B-VIII.0 libraries is $-3.00 \mathrm{pcm} / \mathrm{K}$. Compared to the experimental data of the reactor core, the difference is in the range of 6.9 $\%$ for ENDF/B-VIII.0 libraries. It can be concluded that for the reactor, it is better to use ENDF/B-VIII.0 libraries because the original library is not accurate anymore.
\end{abstract}

(c) 2022 Tri Dasa Mega. All rights reserved.

\section{INTRODUCTION}

Batan is currently continuing to study the Nuclear Power Plant (NPP) which is suitable for use in Indonesia. The study was carried out in terms of the economy, culture, and safety of nuclear power plants that have been operating in the world. However, the study is carried out in stages and continuously because the study of one type of nuclear power plant covers many things, from the performance of the fuel cell parameters to the performance of the reactor as a whole. To support this study, research and studies in terms of safety for certain types of nuclear power plants need to be carried out. Usually, the study of the safety of a nuclear reactor generally starts from the analysis of core parameters such as the reactivity coefficient of the core.

The first stage in designing a reactor as a power plant consists of studying the relationship between the reactor core performance and the fuel cell parameters that meet certain requirements. For the study of the PWR nuclear power plant core, the typical PWR reactor was used. The condition during which the reactor is operated every cycle, there is a change in the reactivity of the core. This change occurs due to the physical properties of the core building blocks, the formation of xenon toxins, and changes in the composition of the fuel. In reactor control, changes in reactivity due to changes in fuel temperature, moderator and

\footnotetext{
${ }^{*}$ Corresponding author. Tel./Fax.:

E-mail: santopaulusrajagukguk98@gmail.com

DOI:10.17146/tdm.2022.24.1.6329
} 
moderator density is called the reactivity coefficient which is designed to have a negative value. Thus the reactor has inherent safety so that if there is an increase in fuel or moderator temperature due to an increase in reactor power, the core reactivity is reduced so that the reactor is safely controlled[1]. The fuel temperature reactivity coefficient (FTRC) is an important parameter for the design, control, and safety of PWR reactors in particular. So it is considered important to carry out accurate calculations for the FTRC parameters with the new cross-section process. The purpose of this calculation is to determine the value of the fuel temperature reactivity coefficient parameter using the new WIMDS library based on nuclear data file ENDF/B-VIII.0[2]. For this reason, cell calculations from the typical PWR reactor using uranium oxide $\left(\mathrm{UO}_{2}\right)$ as fuel and light water as moderators were carried out[3]. The analysis was carried out by calculating the one-dimensional transport completed by the $\mathrm{Sn}$ method.

Determination of the fuel temperature reactivity coefficient parameter is done by modeling the fuel reactor core in the form of a unit cell (pin cell geometry). One unit cell consists of one fuel unit and a moderator. From one equivalent unit cell, cell dimension data is obtained as input data for the cell calculation program known as the annulus. The calculations were carried out with the WIMSD-5B program which contains the old nuclear data library (original) and the WIMSD-5B which has the new nuclear data library (ENDF / B-VIII.0). The reactivity coefficient parameter analysis was carried out by increasing the variance of the fuel temperature. Then the calculation results are analyzed with reference results.

\section{THEORY}

\section{Reactivity Coefficient}

Reactivity refers to changes in the effective multiplication factor of the reactor core caused by the conditions of the reactor. The reactivity of the core will change if there is a change in the operating conditions of the control rod, modification of the reflector or core arrangement, the entry of a neutron source or a neutron absorber into the core[4]. Mathematically, reactivity is expressed in the following equation:

$\rho=\mathrm{k}_{\text {eff }}-1 / \mathrm{k}_{\text {eff }}$

with,

$\rho=$ reactivity

$\mathrm{k}_{\mathrm{eff}}=$ effective multiplication factor
Reactivity can also be defined as the change in the neutron population in one cycle per neutron population at the end of the cycle. The reactor has inherent (internal) factors which can change the reactivity even though the reactor is designed to operate at constant power. The inherent factors that most influence the change in reactivity are changes, increased xenon concentration (fission by-product), changes in the amount of fuel in the reactor core, voids (steam) in the moderator or coolant. The change in reactivity caused by the factors above is expressed in the amount of the reactivity coefficient $(\alpha)$.

\section{Temperature Reactivity Coefficient}

The temperature reactivity coefficient $\left(\alpha_{\mathrm{T}}\right)$ is defined as the partial derivative of the reactivity to changes in temperature[5].

$$
\alpha_{\mathrm{T}}=\delta \rho / \delta \mathrm{T}
$$

with,

$\delta \rho=$ reactivity changed

$\delta \mathrm{T}=$ temperature changed

The value of the temperature reactivity coefficient will determine the stability of the nuclear reaction in the reactor. In the case of a positive temperature reactivity coefficient, it will cause an increase in reactivity if there is an increase in temperature, resulting in an increase in power in the reactor. Conversely, if the temperature reactivity coefficient is negative, then an increase in temperature will cause a decrease in reactivity and continue with a decrease in reactor power so that the reactor tends to be in a safe state.

One of the most common effects in nuclear reactors is the Doppler effect[6]. The Doppler effect is the phenomenon of the widening of the resonant neutron region in the cross-section of the neutron energy as the temperature increases in the fuel. The widening of the resonant region has a very important effect on the phenomenon of absorption of the resonant neutrons (neutrons with a sharp energy curve). It is well known that the macroscopic crosssection of ${ }^{238} \mathrm{U}$ shows high absorption in the resonant neutron energy group. As a result, the resonant neutron absorption rate in the combustion element increases. The temperature increase in the fuel element increases the resonance neutron absorption rate at ${ }^{238} \mathrm{U}$ and results in a decrease in the reactivity of the fuel temperature followed by a decrease in the reactor power[6]. The reactivity coefficient of core moderator temperature is expressed as the change in 
reactivity of the unity of the moderator temperature change,

$$
\alpha_{\mathrm{Tm}}=\delta \rho / \delta \mathrm{T}_{\mathrm{m}}
$$

The reactivity coefficient of the $\alpha_{T m}$ can be calculated by approaching it,

$$
\alpha_{\mathrm{Tm}}=\Delta \rho / \Delta \mathrm{T}_{\mathrm{m}}
$$

The value also depends on the type and fuel. The negative temperature reactivity coefficient supports the safety quality of the reactor operation, where the reactor power will decrease with increasing temperature.

\section{Doppler effect}

The Doppler effect is an event of widening of the peak energy of resonant neutrons, namely neutrons with a clear energy curve in the form of peaks and valleys that are clearly visible on the microscopic absorption cross-sectional curve of ${ }^{238} \mathrm{U}$ in Figure 1. This widening occurs due to the increase in the temperature of the reactor core during the fission reaction take place. As it is known that the resonant neutron in the energy range of $7 \mathrm{eV}-200 \mathrm{eV}$ has a fairly high cross-sectional view of the reaction towards ${ }^{238} \mathrm{U}$ because it has an energy value corresponding to the excitation energy value of the ${ }^{238} \mathrm{U}$ core so that the widening of the resonant neutron peak will increase absorption of neutrons by ${ }^{238} \mathrm{U}$ and resulting in a reduction in the number of thermal neutrons absorbed by ${ }^{235} \mathrm{U}$ so that the $\mathrm{k}_{\text {eff }}$ is reduced.

The effect of increasing temperature on the widening of the resonant neutron peaks is due to the thermal motion of the target nucleus which increases the probability of neutron absorption. The target core oscillates towards its normal position due to an increase in temperature. As a result, not only neutrons with certain energy are absorbed but also other neutrons that have energy that is in the neutron energy interval which previously would have a large absorption probability. This is because if the target nucleus moves towards the incoming neutrons, the neutrons with energy smaller than the energy that should be absorbed, meanwhile the opposite will happen if the target nucleus moves in the same direction as the incoming neutrons. So that the resonant peaks will be wider at high temperatures where the peak resonant neutron energy for the ${ }^{238} U$ atom is $6.67 \mathrm{eV}$. As the temperature of the reactor core increases, the thermal energy of the target core increases, and therefore the neutrons with energy lower and higher than the excitation energy value of the target core will be easily absorbed.

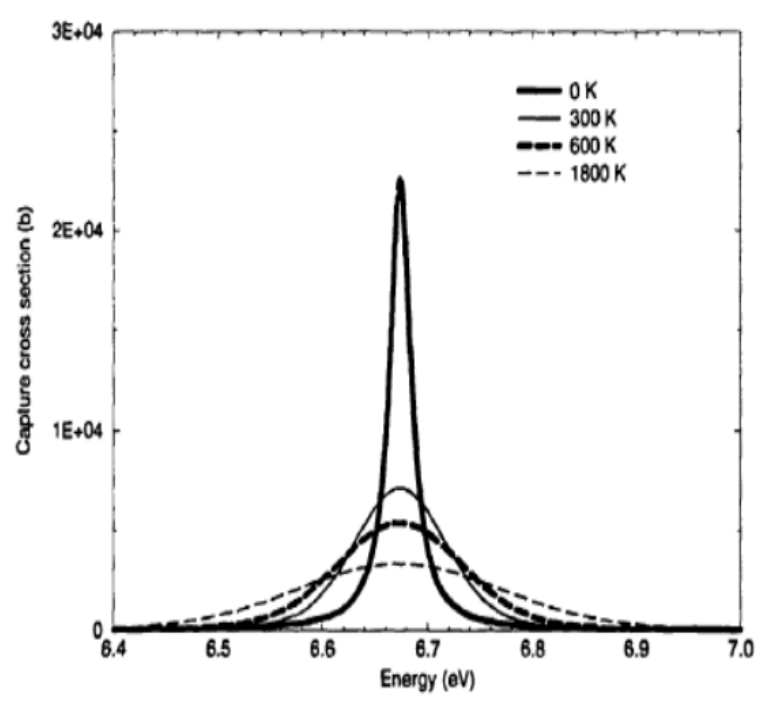

Fig 2. Doppler effect[7]

The widening of the resonant peak (Doppler broadening) will cause a change in fuel reactivity. As it is known that the fission process produces highenergy neutrons which are then moderated through collisions with moderating particles and the neutrons will experience a gradual reduction in energy. When the neutrons reach the resonance energy interval value, the probability of neutrons being absorbed by the ${ }^{238} \mathrm{U}$ nucleus will be very large, while the opposite happens at ${ }^{235} \mathrm{U}$. This event leads to a decrease in reactor reactivity. Cross-section of ${ }^{238} U$ absorption in the resonant region decreases with increasing temperature, however, the neutron flux in the resonant region is getting bigger, so that it directly affects the thermal neutron absorption by ${ }^{235} \mathrm{U}$. The movement of neutrons in the reactor core is very complicated because the neutrons move randomly and collide repeatedly with the target and moderator nuclei $\left(\mathrm{H}_{2} \mathrm{O}\right)$. As a result of this movement, neutrons that were previously in one part of the reactor and moving in a certain direction and with certain energy at another time will appear in another part with a different direction of movement and energy. In this case, the neutron is said to be transported from the initial space and energy region to the second space and energy region. The study of this phenomenon is often referred to as the transport theory[8]. The WIMS program containing the transport equation was solved by the $\mathrm{Sn}$ method (discrete ordinate) used for lattice calculation. Lattice calculations are performed to obtain the neutron power distribution and the infinite multiplication factor. As input in lattice calculations are nuclear isotope data with multiple energy groups and a description of the reactor that can be 
represented by unit cells or macrocells. Calculation of the value of $\mathrm{k}_{\text {eff }}$ is done by using the leakage factor which can be done with the buckling correction approach.

\section{BRIEF DESCRIPTION OF PWR CORE}

PWR is a Pressurized Water Reactor type designed by Westinghouse. PWR reactor has a core configuration as shown in Figure 1. Core PWR at the beginning of the cycle (BOC) is composed of 3 types of enrichment, namely $2.4 \%, 3.1 \%$, and $3.9 \%$ consisting of 49 fuel assemblies, 48 fuel assemblies, 48 fuel assemblies, refectively[9]. The number of fuel that makes up the PWR reactor core is 145 fuel assemblies. PWR active core dimensions, fuel, and reflector devices are summarized in Table 1. PWR reactor has a pellet-type fuel cylinder with $\mathrm{UO} 2$ and the fuel the cladding is Zircalloy-4[10].

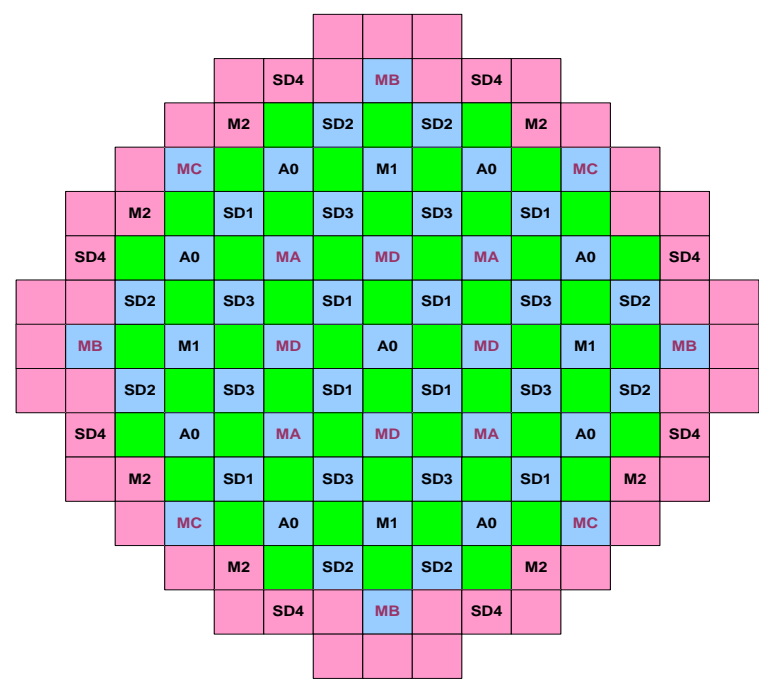

Fig 1. PWR core configuration [11]

In the good fuel cladding at the top or the bottom, there is a space used to accommodate gases fission products. Each set of the fuel assembly contains 269 (17 x 17) elements that are consists of 264 pieces of fuel elements and 24 a guide thimble element and one instrumentation tube. The fuel is also equipped with control devices a total of 24 pieces on one device fuel which is often called RCCA (rod cluster control assemblies). The main material from forming the control element is $\mathrm{Ag} \mathrm{In-Cd}$, while the cladding is zircaloy material. Control element device RCCA is used to control changes in reactivity and power distribution axial. Apart from RCCA, there are also devices GRCA control elements (gray rod cluster assemblies) on the core of the PWR reactor used to regulate the reactivity of the core according to changes in load. Light water used as a coolant and moderator which is mixed with the liquid boron functions as a neutron absorber[12]. The concentration of liquid boron varies in amount according to changes in its reactivity change due to the change in the burn fraction inside the core.

Table 1. The core data of a Typical PWR[13]

\begin{tabular}{ll}
\hline Plant data & Values \\
\hline Net electrical output, MW & 1175 \\
Fuel assembly & $17 \times 17$ \\
Number of fuel rods & 264 \\
Number of guide tubes & 24 \\
In-core instrumentation & 1 \\
Full length (without control spider), mm & 4058 \\
Width, mm & 214 \\
Rod pitch, mm & 12.6 \\
Mass of $\mathrm{UO}_{2}, \mathrm{Kg}$ & 460 \\
Initial internal pressure $(\mathrm{He})$, bar & 24.1 \\
The outside diameter of the fuel rod, mm & 9.5 \\
Fuel pellet material & $\mathrm{UO}{ }_{2}$ \\
Density, g/cc & 10.4 \\
Fuel temperature, ${ }^{\circ} \mathrm{C}$ & 811 \\
Coolant temperature,${ }^{\circ} \mathrm{C}$ & 570 \\
Cladding temperature, ${ }^{\circ} \mathrm{C}$ & 620 \\
Cladding material & Zircaloy-4 \\
Cladding thickness, mm & 0.57 \\
\hline
\end{tabular}

\section{METHODOLOGY}

\section{Cell Calculation}

The WIMS program uses transport theory to calculate neutron flux as a function of energy and space in a one-dimensional cell. To solve the transport equation, the DSN (discrete ordinates) method is used. Then this program package is used for the fuel cell calculation phase. This program functions to process the input from the chancellor's core to produce the output in the form of a macroscopic cross-sectional constant of the reactor core material. In this program, the reactor core element is modeled as a collection of annulus composed of meat, cladding, moderator, and extra region. The input prepared for the WIMS program package is in the form of elemental composition reactor fuel, variations in the temperature value of the fuel element. The calculations for the lattices have been done with hot zero power condition $\mathrm{Tf}$ and $\mathrm{T}_{\mathrm{m}}=600 \mathrm{~K}$, meanwhile for hot full power condition $\mathrm{T}_{\mathrm{f}}=900 \mathrm{~K}$ and $\mathrm{T}_{\mathrm{m}}=600 \mathrm{~K}[14]$. 
In the first part, the neutron spectrum in a certain geometry and groups is calculated according to the program library (69 groups), and is used to summarize the amount of power into only 4 groups (few groups), namely[15]:

-Fast neutrons, groups 1-5 with an energy of 0.821 $\mathrm{MeV}<\mathrm{E} \sim 10 \mathrm{MeV}$.

- Retarding neutrons, groups 6-15 with energies of $5,531 \mathrm{eV}<\mathrm{E} \sim 0.821 \mathrm{MeV}$.

-Resonant neutrons, group 16-45 with energy 0.625 $\mathrm{eV}<\mathrm{E} \sim 5,531 \mathrm{keV}$.

- Thermal neutrons, groups 46-69 with energies $<0.615 \mathrm{eV}$.

The macroscopic cross-section of the neutron power, which is required as the coefficient of the multigroup equation, is obtained directly from the atomic density of the isotope given in the program input as well as the microscopic cross-section of the program library.

In the second part, many groups were calculated. The cell is composed of 4 regions, where index 1 is for the fuel meat region, index 2 for cladding, index 3 for moderators, and index 4 for the extra region. The dimensions and composition of each region are derived from program inputs. After obtaining the multi-group spectrum in the four regions, the multigroup constant was summarized into 4 groups.

The $\mathrm{UO}_{2}$ fuel cell pin is the same for the LWR reactor type with a $17 \times 17$ fuel device. The $3.0 \% \mathrm{U}$ 235 enrichment in fuel is made to produce a fuel fraction of $40 \mathrm{GWd} / \mathrm{t}$. in one cycle (2 years of full power operation $=$ full power day). Cell pin geometry configuration with the size of the fuel radius $r_{1}=0.4 \mathrm{~cm}, r_{2}=0.45 \mathrm{~cm}$ and $r_{3}=0.677 \mathrm{~cm}$ where the outer radius is the same as a square with $/ 2=0.6 \mathrm{~cm}[14]$. The configuration of the fuel cell pin geometry is presented in Figure 3 .

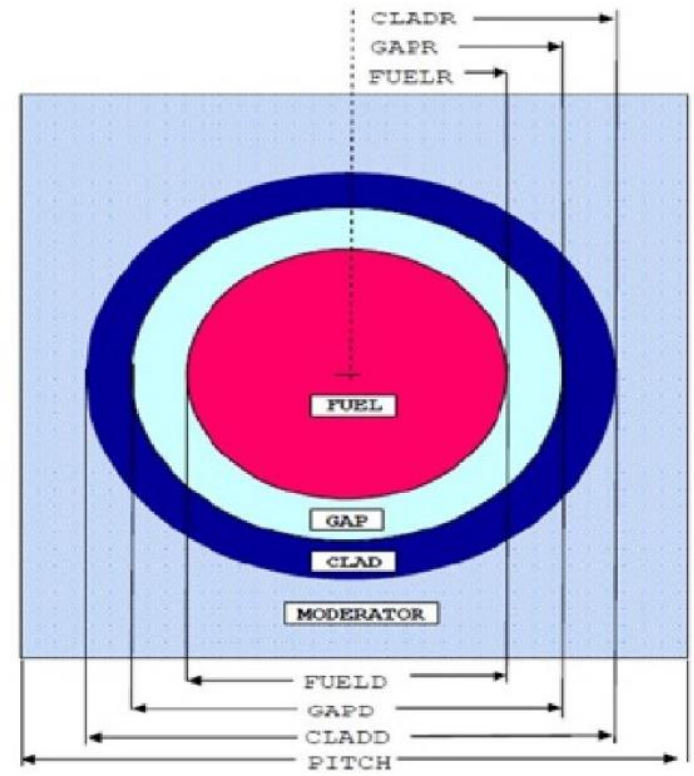

Fig 3. The unit cell of PWR pin [16]

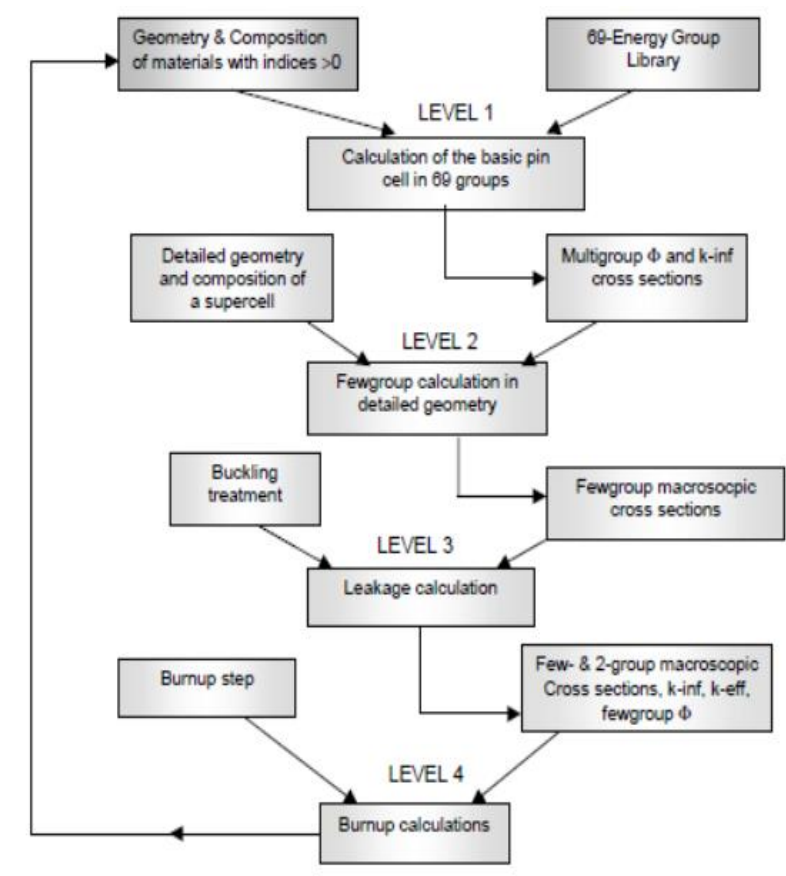

Fig 4. Flowchart of WIMS code [17]

The WIMS program is only capable of calculating one-dimensional neutron transport, so it is necessary to do modeling of the core cells. Cell modeling is used to calculate the generation of group constants in 4 energy groups. Calculation of cells with the WIMS program package from the reactor cell unit type LWR consisting of fuel clusters with a square pitch arrangement as shown in Figure 3. Then the cell unit dimensions are calculated, one unit cell will consist of one fuel and a moderator. The area of moderators surrounding the fuel is 
$\mathrm{L}=(1.26)^{2}-3.14 \times(0.475)^{2}=0.879 \mathrm{~cm}$

then the radius of the moderator around the fuel element is the root of the area above divided by 3.14 and the result is $0.53 \mathrm{~cm}$. From the equivalent unit cell, the cell dimension data is obtained as input data for the WIMS program known as the annulus as shown in Figure 3. The atomic density that forms the fuel pin is presented in Table 1. The generation of group constants is intended to obtain the average value of group constants in a cell by homogenizing the cell. To obtain group constant values that correspond to the core conditions, the core buckling value $\left(\mathrm{B}_{\mathrm{z}}{ }^{2}\right)$ was obtained from the experiment as in Table 1. The calculation of group constants was carried out for the core constituent materials under conditions as above. The core $\mathrm{k}_{\mathrm{inf}}$ and the reaction rate were calculated by enriching the fuel for each reactor as in Table 1. Pin cell

geometry, temperature conditions are as shown in Table1. To perform coefficient analysis Reactivity of the moderator temperature is carried out as follows: Calculation of cells at room temperature conditions (temperature $\mathrm{T}_{0}$ ) is carried out using the leakage factor (buckling) from the experimental results. Then calculate the cells with hot conditions (temperature $\mathrm{T}_{1}$ ). In this case the fuel temperature, cladding, moderator, and density change. Then the coefficient The reactivity is calculated by equation (2) and the calculation flow chart is presented in Figure 4.

\section{RESULTS AND DISCUSSION}

From the calculation results of the WIMSD-5B using existing and newest library programs, it is obtained that the values of $\mathrm{k}_{\text {eff }}$ PWR core and fuel temperature coefficient reactivity using ENDFBVI. 8 is presented in Table 2 .

Tabel 2. Coefficient reactivity of doppler for typical PWR using ENDF/B-VI.8

\begin{tabular}{llllllll}
\hline $\begin{array}{l}\text { Fuel } \\
\text { enrich } \\
(\mathrm{Wt} \%)\end{array}$ & $\begin{array}{l}\mathrm{K}_{\text {cold }} \\
(\% \Delta \mathrm{k} / \mathrm{k})\end{array}$ & $\begin{array}{l}\mathrm{K}_{\text {hot }} \\
(\% \Delta \mathrm{k} / \mathrm{k})\end{array}$ & $\begin{array}{l}\rho_{\text {cold }} \\
(\%)\end{array}$ & $\begin{array}{l}\rho_{\text {hot }} \\
(\%)\end{array}$ & $\begin{array}{l}\alpha_{\mathrm{f}} \\
(\mathrm{pcm} / \mathrm{K}) \\
(\mathrm{WIMS})\end{array}$ & $\begin{array}{l}\alpha_{\mathrm{f}} \\
(\mathrm{pcm} / \mathrm{K}) \\
(\mathrm{MCNP})\end{array}$ & $\begin{array}{l}\alpha_{\mathrm{f}} \\
(\mathrm{pcm} / \mathrm{K}) \\
(\mathrm{exp})\end{array}$ \\
\hline 0.711 & 0.662460 & 0.654612 & -0.5095 & -0.5276 & $-6,03$ & $-5.4 \pm 0.8$ & $-3.6 \pm 0.7$ \\
1.600 & 0.956271 & 0.946082 & -0.0457 & -0.0569 & -3.73 & $-3.6 \pm 0.3$ & $-3.4 \pm 0.4$ \\
2.400 & 1.093810 & 1.082877 & 0.0858 & 0.0765 & -3.10 & $-2.7 \pm 0.3$ & $-2.9 \pm 0.4$ \\
3.100 & 1.171480 & 1.160236 & 0.1464 & 0.1381 & -2.76 & $-2.6 \pm 0.3$ & $-3.0 \pm 0.4$ \\
3.900 & 1.234334 & 1.222433 & 0.1898 & 0.1819 & -2.63 & $-2.4 \pm 0.2$ & $-2.9 \pm 0.3$ \\
\hline
\end{tabular}

From the calculation using the WIMSD code, it is found that the $\mathrm{k}_{\text {eff }}$ value increases with increasing fuel enrichment. The $\mathrm{k}_{\text {eff }}$ value at the temperature of the fuel and moderator were $600 \mathrm{~K}$ for the smallest $0.711 \mathrm{wt} \%$ enrichment, is 0.662460 , and the highest at $3.9 \mathrm{wt} \%$ fuel enrichment is 1.234334 . For the fuel, the temperature is increased to $900 \mathrm{~K}$ and the moderator temperature is $600 \mathrm{~K}$, the $\mathrm{k}_{\text {eff }}$ value decreases so that it can be said that the fuel reactivity coefficient is negative. This is in accordance with the typical PWR design. The parameter of fuel temperature coefficient reactivity from calculation results compare to experimental data for ENDF/BVI.8 the biggest around $67 \%$ But if it is compared to the reference (MCNP code) is around $11,7 \%$. The calculation result that is closest to the reference is the $1.6 \mathrm{wt} \%$ enrichment, the difference is around 3.6\%, but if the experimental results are $3.1 \mathrm{wt} \%$ enrichment, the difference is around $6.9 \%$.

Tabel 3. Coefficient reactivity of doppler for typical PWR using ENDF-B.VII.0

\begin{tabular}{llllllll}
\hline $\begin{array}{l}\text { Fuel } \\
\text { enrich } \\
(\mathrm{Wt} \%)\end{array}$ & $\begin{array}{l}\mathrm{K}_{\mathrm{cold}} \\
(\% \Delta \mathrm{k} / \mathrm{k})\end{array}$ & $\begin{array}{l}\mathrm{K}_{\text {hot }} \\
(\% \Delta \mathrm{k} / \mathrm{k})\end{array}$ & $\begin{array}{l}\rho_{\text {cold }} \\
(\%)\end{array}$ & $\begin{array}{l}\rho_{\text {hot }} \\
(\%)\end{array}$ & $\begin{array}{l}\alpha_{\mathrm{f}} \\
(\mathrm{pcm} / \mathrm{K}) \\
(\mathrm{WIMS})\end{array}$ & $\begin{array}{l}\alpha_{\mathrm{f}} \\
(\mathrm{pcm} / \mathrm{K}) \\
(\mathrm{MCNP})\end{array}$ & $\begin{array}{l}\alpha_{\mathrm{f}} \\
(\mathrm{pcm} / \mathrm{K}) \\
(\mathrm{exp} .)\end{array}$ \\
\hline 0.711 & 0.664775 & 0.656838 & -0.5043 & -0.5224 & -6.03 & $-5.4 \pm 0.8$ & $-3.6 \pm 0.7$ \\
1.600 & 0.959548 & 0.949251 & -0.0422 & -0.0535 & -3.77 & $-3.6 \pm 0.3$ & $-3.4 \pm 0.4$ \\
2.400 & 1.097234 & 1.086187 & 0.0886 & 0.0793 & -3.10 & $-2.7 \pm 0.3$ & $-2.9 \pm 0.4$ \\
3.100 & 1.174892 & 1.163533 & 0.1489 & 0.1405 & -2.80 & $-2.6 \pm 0.3$ & $-3.0 \pm 0.4$ \\
3.900 & 1.237681 & 1.225663 & 0.1920 & 0.1841 & -2.63 & $-2.4 \pm 0.2$ & $-2.9 \pm 0.3$ \\
\hline
\end{tabular}

The result of the calculation using ENDF/B-VII.0 of the typical PWR core for fuel temperature coefficient reactivity is presented in Table 3 . From the table, it can be seen that the higher the 
temperature, the smaller the $\mathrm{k}_{\text {eff }}$ values. In general, causing the $\mathrm{k}_{\text {eff }}$ value to decrease. The results of the calculation for fuel temperature coefficient reactivity using ENDF/B-VII.0 are almost the same as ENDF/B-VI.8. The differences are just for 1.6 and $3.1 \mathrm{wt} \%$ enrichments and they are not significant for the fuel temperature coefficient reactivity parameter because small difference. The result of the calculation using ENDF/B-VII.1 of the typical PWR core for fuel temperature coefficient reactivity is presented in Table 4.

Tabel 4. Coefficient reactivity of doppler for typical PWR using ENDF-B.VII.1

\begin{tabular}{cccccccc}
\hline $\begin{array}{c}\text { Fuel } \\
\text { enrich. } \\
(\mathrm{Wt} \%)\end{array}$ & $\begin{array}{c}\mathrm{K}_{\text {cold }} \\
(\% \Delta \mathrm{k} / \mathrm{k})\end{array}$ & $\begin{array}{c}\mathrm{K}_{\text {hot }} \\
(\% \Delta \mathrm{k} / \mathrm{k})\end{array}$ & $\begin{array}{c}\rho_{\text {cold }} \\
(\%)\end{array}$ & $\begin{array}{c}\rho_{\text {hot }} \\
(\%)\end{array}$ & $\begin{array}{c}\alpha_{\mathrm{f}} \\
(\mathrm{pcm} / \mathrm{K}) \\
(\mathrm{WIMS})\end{array}$ & $\begin{array}{c}\alpha_{\mathrm{f}} \\
(\mathrm{pcm} / \mathrm{K}) \\
(\mathrm{MCNP})\end{array}$ & $\begin{array}{c}\alpha_{\mathrm{f}} \\
(\mathrm{pcm} / \mathrm{K}) \\
(\mathrm{exp})\end{array}$ \\
\hline 0.711 & 0.664822 & 0.656887 & -0.5042 & -0.5223 & -6.03 & $-5.4 \pm 0.8$ & $-3.6 \pm 0.7$ \\
1.600 & 0.959495 & 0.949199 & -0.0422 & -0.0535 & -3.77 & $-3.6 \pm 0.3$ & $-3.4 \pm 0.4$ \\
2.400 & 1.097157 & 1.086114 & 0.0886 & 0.0793 & -3.10 & $-2.7 \pm 0.3$ & $-2.9 \pm 0.4$ \\
3.100 & 1.174808 & 1.163453 & 0.1488 & 0.1405 & -2.76 & $-2.6 \pm 0.3$ & $-3.0 \pm 0.4$ \\
3.900 & 1.237595 & 1.225581 & 0.1919 & 0.1841 & -2.60 & $-2.4 \pm 0.2$ & $-2.9 \pm 0.3$ \\
\hline
\end{tabular}

From the table, it can be seen that in general causing the $\mathrm{k}_{\text {eff }}$ value decreases with higher fuel temperature. The results of calculation for fuel temperature coefficient reactivity using are ENDF/B-VII.1 almost the same as ENDF/B-VII.0. The differences are just for 3.1 $\mathrm{wt} \%$ and $3.9 \mathrm{wt} \%$ enrichments and they are not significant for the fuel temperature coefficient reactivity parameter, but compare to the experiment data, they are better than reference.

Tabel 5. Coefficient reactivity of doppler for typical PWR using ENDF-B.VIII.0

\begin{tabular}{cccccccc}
\hline $\begin{array}{c}\text { Fuel } \\
\text { enrich. } \\
(\mathrm{Wt} \%)\end{array}$ & $\begin{array}{c}\mathrm{K}_{\text {cold }} \\
(\% \Delta \mathrm{k} / \mathrm{k})\end{array}$ & $\begin{array}{c}\mathrm{K}_{\text {hot }} \\
(\% \Delta \mathrm{k} / \mathrm{k})\end{array}$ & $\begin{array}{c}\rho_{\text {cold }} \\
(\%)\end{array}$ & $\begin{array}{c}\rho_{\text {hot }} \\
(\%)\end{array}$ & $\begin{array}{c}\alpha_{\mathrm{f}} \\
(\mathrm{pcm} / \mathrm{K}) \\
(\mathrm{WIMS})\end{array}$ & $\begin{array}{c}\alpha_{\mathrm{f}} \\
(\mathrm{pcm} / \mathrm{K}) \\
(\mathrm{MCNP})\end{array}$ & $\begin{array}{c}\alpha_{\mathrm{f}} \\
(\mathrm{pcm} / \mathrm{K}) \\
(\mathrm{exp} .)\end{array}$ \\
\hline 0.711 & 0.669913 & 0.662070 & -0.4927 & -0.5104 & -5.90 & $-5.4 \pm 0.8$ & $-3.6 \pm 0.7$ \\
1.600 & 0.963568 & 0.953423 & -0.0378 & -0.0489 & -3.70 & $-3.6 \pm 0.3$ & $-3.4 \pm 0.4$ \\
2.400 & 1.099668 & 1.088799 & 0.0906 & 0.0816 & $-3,00$ & $-2.7 \pm 0.3$ & $-2.9 \pm 0.4$ \\
3.100 & 1.176056 & 1.164885 & 0.1497 & 0.1416 & $-2,70$ & $-2.6 \pm 0.3$ & $-3.0 \pm 0.4$ \\
3.900 & 1.237602 & 1.225798 & 0.1919 & 0.1842 & -2.59 & $-2.4 \pm 0.2$ & $-2.9 \pm 0.3$ \\
\hline
\end{tabular}

WIMS calculations for fuel temperature reactivity coefficient parameters using the new nuclear data $\mathrm{ENDF} / \mathrm{B}-\mathrm{VIII} .0$ give consistent results to the design, whereas calculations using old nuclear data (ENDF/B-VI.8) are inconsistent or far from the design value. This is because the fission spectrum in the old nuclear data is different from the fission spectrum from the new nuclear data and the resonance handling in the physical reaction rate corresponds to the resonance of the LWR-type UO2 fuel. The reaction rates in the cell calculations for the isotopes ${ }^{235} \mathrm{U}$ and ${ }^{238} \mathrm{U}$ at the energy of the first group did not match the predictions and the effect was the rapid fission reaction of ${ }^{238} \mathrm{U}$. This is because the group energy mesh at the fast range is too coarse to be even more accurate. The fission equalization spectrum between ${ }^{235} \mathrm{U}$ and ${ }^{238} \mathrm{U}$ on the new nuclear data (ENDF/B-VIII.0) will produce a good crosssectional profile resulting in parameter values that are in accordance with the design. The rate of reaction of ${ }^{238} \mathrm{U}$ at epithermal and thermal energy yields good values against the reference. This shows that the effect of resonance on the cross-sectional generation is well calculated.

\section{CONCLUSION}

Calculations using WIMSD-5B based on the new nuclear data ENDFB-VIII.0 give more representative results with the 4 groups of neutron energy models, the resulting fuel temperature reactivity coefficient parameter values are in accordance with the reference results, namely -3.0 $\mathrm{pcm} / \mathrm{K}$ while the reference calculation results are calculated with MCNP- $4 \mathrm{~b}$ the result is $-2.7 \mathrm{pcm} / \mathrm{K}$ for the typical PWR reactor while for the experimental data is $-2.9 \mathrm{pcm} / \mathrm{K}$. From the results of these calculations, the difference is about $6.9 \%$. 


\section{ACKNOWLEDGMENT}

The authors wish to thank the Head of PTKRNBatan and the coordinator of BFTR-PTKRN Batan for their kindly help and useful discussions when doing the research.

\section{AUTHOR CONTRIBUTION}

Tukiran Surbakti carried out core modeling in the core calculation code, Santo Paulus Rajagukguk carried out cell calculation using WIMSD-5B. Tukiran Surbakti participated as a reviewer and did data analysis. Santo Paulus Rajagukguk and Tukiran Surbakti as main contribution of this paper. All authors read and approved the final version of the manuscript.

\section{REFERENCES}

1. Pinem S., Sembiring T.M., Surbakti T. Core Conversion Design Study of TRIGA Mark 2000 Bandung using MTR Plate Type Fuel Element. Int. J. Nucl. Energy Sci. Technol. 2018. 12(3):222-238.

2. Surbakti T., Purwadi P. Analysis of Neutronic Safety Parameters of the Multi-Purpose Reactor-Gerrit Augustinus Siwabessy (RSGGAS) Research Reactor at Serpong. J. Penelit. Fis. dan Apl. 2019. 9(1):78-91.

3. Surian P., Tagor M. S., Tukiran S. Verifikasi Program PWR-fuel Dalam Manajemen Bahan Bakar PWR. JSTNI. 2015. 16(1): 53-62.

4. Dawahra S., Khattab K., Saba G. Extending the Maximum Operation Time of the MNSR Reactor. Appl. Radiat. Isot. 2016. 115:256-261.

5. Dawahra S., Khattab K., Saba G. Calculation and Comparison of Xenon and Samarium Reactivities of the HEU, LEU Core in the Low Power Research Reactor. Appl. Radiat. Isot. 2015. 101:27-32.

6. Surbakti T., Pinem S., Suparlina L. Dynamic Analysis on the Safety Criteria of the Conceptual Core Design in MTR-type Research Reactor. Atom Indonesia. 2018. 44(2):89-97.

7. Surbakti T., Pinem S., Sembiring T.M., Hamzah A., Nabeshima K. Calculation of Control Rods Reactivity Worth of RSG-GAS First Core using Deterministic and Monte Carlo Methods. Atom Indonesia. 2019. 45(2):69-79.

8. Pinem S., Sembiring T.M., Liem P.H. Neutronic and Thermal-hydraulic Safety Analysis for the Optimization of the Uranium Foil Target in the RSG-GAS Reactor. 2016.
42(3):123-128.

9. Iman K., Surian P., Tagor M.S., and Tukiran S. Evaluation of Fuel Loading Pattern of PWR Core Using PWR-FUEL Code. : AIP Conference Proceedings. 2019. 2180,020007.

10. Hend S., Moustafa A., Riham R., Hesham M. Core Neutronic Characterization of Advanced Pressurized Water Reactor. Journal of Nuclear and Particle Physics. 2021. 11(1): 7-14.

11. Zakir, M., Sarkar M., and Hossain A. Analysis of Neutronics and Thermal-Hydraulic Behavior in a Fuel Pin of Pressurized Water Reactor (PWR). World Journal of Nuclear Science and Technology. 2019. 9: 74-83.

12. Nicholas R.B., Hans L., Arnold A., Gilad R., Michael T. Neutronic Evaluation of a PWR with Fully Ceramic Microencapsulated Fuel. Part II: Nodal Core Calculations and Preliminary Study of Thermal-Hydraulic Feedback. Annals of Nuclear Energy. 2013. 62: 548-557.

13. Pinem S., et al. PWR Fuel Macroscopic Cross Section Analysis for Calculation Core Fuel Management Benchmark. 2019. J. Phys.: Conf. Ser. 1198022065.

14. Surian Pinem et al. Reactivity Coefficient Calculation for AP1000 Reactor Using the NODAL3 Code. 2018. J. Phys.: Conf. Ser. 962 012057.

15. Surbakti T., Imron M. Fuel Burn-up Calculation for Working Core of the RSG-GAS Research Reactor at Batan Serpong. J. Penelit. Fis. dan Apl. 2017. 7(2):89-101.

16. Michael A.P., Sen R. S., Abderrafi M.O., Gilles Y., Brian B. Neutronic Analysis of the Burning of Transuranics in Fully Ceramic Microencapsulated Tri-isotropic Particle-fuel in a PWR. Nuclear Engineering and Design. 2012. 252: 215-225.

17. Pinem S., Surbakti T., Sembiring T., et al. Optimization of Radioisotope Production at RSG-GAS Reactor using Deterministic Method. Journal Teknologi Indonesia. 2016. 1 (2):12-18. 